\title{
La espera íntima y estatal, en las obras de los hermanos Eduarda y Lucio Mansilla ${ }^{1}$
}

\author{
Claudia Torre \\ Universidad Nacional de Hurlingham. Instituto de Educación
}

\begin{abstract}
Resumen
Cuando Roland Barthes, en Fragments dun discourse amoureux, analiza la figura de la espera sugiere que esta es un tumulto de angustia, con una escenografía organizada y manipulada, una solemnidad y un sentido de las proporciones que se configura en actos. El desenlace de esta trama deviene abandono o agradecimiento. En la literatura argentina del siglo XIX, esta figura del discurso de los afectos puede leerse en la encrucijada de la intimidad y la trama social. El artículo refiere dos obras de los hermanos Mansilla: El médico de San Luis (1860) de Eduarda Mansilla y Una excursión a los indios ranqueles de Lucio V. Mansilla, publicada diez años después. Las dos obras tematizan la pasión/sujeción de la espera, que es analizada en ambas, a partir de la idea de una narración pública que rodea y se filtra sobre las formas y prácticas de la vida cotidiana y de las historias de familia.
\end{abstract}

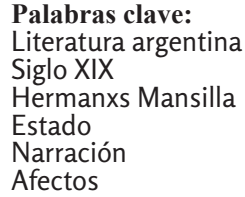

\begin{abstract}
When Roland Barthes in Fragments dun discourse amoureux, analyzes the figure of the wait, he suggests that this is a tumult of anguish, with an organized and manipulated scenery, a solemnity and a sense of the proportions that are configured in acts. The outcome of this plot becomes abandonment or thanks. In Argentine literature of the nineteenth century, this figure of the discourse of affections can be read at the crossroads of intimacy and social plot. The article refers to two works by the Mansilla brothers: In Elmédico de San Luis (1860) by Eduarda Mansilla and Una excursión a los indios ranqueles by Lucio V. Mansilla, published ten years later. Both works thematize the passion/subjection of waiting, which is analyzed in both works, based on the idea of a public narration that surrounds and filters on the forms and practices of daily life and family stories.
\end{abstract}

1 Este artículo se inscribe en el marco del Proyecto de Investigación: "Narración y Estado en la literatura argentina del siglo XIX. Un estudio de las obras de los hermanos Mansilla, en sintonía" que dirijo junto con Marcos Seifert, en la Universidad Nacional de Hurlingham. 
Keywords:

Argentine literature

19 th century

Mansilla Brothers

State

Narration

Affections

\section{Los sentimientos que desata la espera}

Cuando Roland Barthes, en Fragmentos de un discurso amoroso, analiza la figura de la espera sugiere que esta es un tumulto de angustia, con una escenografía organizada y manipulada, una solemnidad y un sentido de las proporciones que se configuran en actos. El desenlace de esta trama deviene abandono o agradecimiento. En la espera, el sentido de las proporciones se altera. Todo adquiere una dimensión escenográfica en la que, quien está esperando sufre, siente angustia, su expectativa desata afecciones diversas. Asimismo, la angustia de la espera tiene sus momentos: suposiciones, furia, ira, sentimientos de abandono y, en el momento en el que, por las causas que fueran, el sujeto deja de esperar o en el que ese dejar de esperar finaliza, el desenlace puede tornarse apacible, o puede manifestar por parte del sujeto que ha esperado el enojo o la gratitud sin más. Es cierto que la espera tiene sus momentos apagados pero su punto central es la sujeción o, en el decir de Barthes, el encantamiento, una suerte de nomadismo impuesto: no debo moverme, aquí estoy esperando. En este sentido, la espera puede asociarse a la melancolía en el sentido de permanecer en una posición de ensimismamiento, o puede oponerse a ella, dado que el/la melancólico/a no espera, no tiene expectativa a futuro. Quien espera tiene entonces expectativa y será, de este modo, compensado/a o defraudado/a.

Ahora bien, ¿es posible pensar esta figura y los sentimientos que desata en la literatura argentina del siglo XIX? Creemos que sí y que, como se señala en la presentación del dossier en el que se inserta este trabajo, el siglo XIX se presenta en su literatura como un reservorio/enciclopedia de las emociones, llamadas estados del alma. Ahora bien, ese universo emocional, atravesado por la estética del romanticismo y por el cultivo de las formas de vida de lo privado, no puede pensarse sin su dimensión social.

Aquí particularmente haremos hincapié en esa esfera para pensar las formas de una narración del Estado que promueve un sujeto republicano, liberal, cuya matriz de organización social es heterosexual y patriarcal. Y también prestaremos atención a ciertas configuraciones de la organización religiosa (catolicismo/protestantismo) con su contrapartida, el laicismo estatal, que inciden de manera crucial en las formas que van tomando los sentimientos de los personajes en las narraciones.

¿Qué signo tiene la exaltación emocional de esos sentimientos? ¿Qué se espera y quiénes esperan en la literatura argentina del siglo XIX?

\section{La obra de los hermanos Mansilla en sintonía}

Como señalamos en el apartado anterior, la espera en los relatos decimonónicos puede leerse en la encrucijada de la intimidad y la trama social. En este sentido proponemos pensar estas figuras en dos obras de dos escritorxs hermanxs: Eduarda Mansilla y Lucio Victorio Mansilla, hijos de Agustina Ortiz de Rosas y de Lucio Norberto Mansilla y sobrinos de Juan Manuel de Rosas. 
La producción de los hermanos Mansilla constituye una entrada privilegiada a las relaciones entre narración y Estado durante el período de constitución del Estado argentino debido a la diversidad textual (crónicas, folletines, diarios de viaje, escritos periodísticos, cuentos, causeries) que permite dar cuenta de los puntos de cruce entre la vida pública y las pugnas políticas de la elite, por un lado, y las narraciones de lo cotidiano que constituyen el corazón de la intimidad, por el otro. Nuestra hipótesis general sostiene que el posicionamiento en la política y en la escritura de los Mansilla -que conjuga el cosmopolitismo y la pertenencia familiar rosista (en tanto sobrinos del gobernador Rosas) - es central para analizar la intersección entre las narraciones sociales/familiares y las ficciones estatales, en un momento en que puede observarse un despliegue de relatos impulsados por el proyecto liberal. Además, es necesario tener en cuenta que tanto las vidas como las obras de cada uno de estos hermanos cubren la mitad del siglo XIX, momento en que el Estado argentino está en permanente transformación. En ese contexto y entramado narrativo, las voces de los Mansilla deben ser consideradas en conjunto, para comprender el carácter de un problema que no se explica simplemente por las características autorales de cada uno de ellos por separado, sino por una consideración conjunta que permite comprender el lugar de una familia de elite ante el Estado, la prensa y la opinión pública y las diferencias que despliega la cuestión de género puesta en juego en el análisis de ambos autores.

Al mismo tiempo, esto pone de manifiesto, tanto los diferentes posicionamientos ante el rol de las mujeres como el lugar desplazado de Eduarda Mansilla en el canon literario argentino. A pesar de esas diferencias, el análisis conjunto permite dar cuenta de un posicionamiento que consiste en la insistencia crítica o disidente frente al proyecto liberal aunque sin abandonar ese lugar de enunciación hacia el interior mismo de un nosotros del poder, una postura que combina autobiografía y ficción para señalar las exclusiones, para los otros a los que el Estado se aproxima, excluyéndolos.

La novela El médico de San Luis publicada en 1860 por Eduarda Mansilla (con el seudónimo Daniel) cuenta la historia de un médico extranjero de provincia, que espera al "hijo descarriado" por la montonera federal y que aguarda, también, en clave protestante, su "redención". Si bien hay otras tramas (tales como la llegada del compatriota Gifford y el pedido de ayuda que un amigo del narrador formula al médico, a fin de que este interceda ante un juez corrupto y logre su desvinculación laboral, así como tramas amorosas e ingenuas asociadas a las hijas mellizas), la que nos interesa es esa partida del hijo y esa espera del padre, espera paciente confiando en su redención.

En sintonía con esta focalización en la novela de Eduarda Mansilla, pondremos atención en el relato que su hermano Lucio Victorio hizo diez años después en Una excursión a los indios ranqueles. Se trata de la historia en la que el entonces coronel del Ejército argentino cuenta que espera en el Fuerte Sarmiento la autorización de su superior castrense para internarse con una comisión tierra adentro en las tolderías de los caciques Mariano Rosas y Baigorrita, esto es, en ese universo complejo que fue Leubucó. El objetivo era firmar un acuerdo con los indios ranqueles, en el marco de un proyecto mayor: llevar la frontera hasta el río Quinto. Mansilla solicita a su jefe militar, el coronel Arredondo, un permiso para adentrarse con una comitiva formada por cuatro oficiales, once soldados y dos sacerdotes. Dice que espera este permiso o concretamente abandona la espera de este permiso para expedicionar hacia los toldos. Lo cierto es que, al regresar de esa marcha no autorizada a la que él llamará excursión, recibe una sanción disciplinaria que le impone volver a Buenos Aires. Es allí donde publicará el relato de este viaje en el periódico La Tribuna para convencer a la opinión pública de Buenos Aires de su inocencia y de lo injusta e impropia que resultaba la sanción de la que había sido objeto. 
Tanto el relato de Eduarda, que cuenta las vicisitudes de una familia en territorio de frontera, como el de Lucio, que ofrece la experiencia del viaje tierra adentro, refieren la pasión/sujeción de la espera a partir de una narración pública que rodea y se filtra sobre las formas de la vida cotidiana y de las historias de familia.

\section{¿Qué es y qué sentimientos desata la espera?}

Si la espera, en la imaginación cultural, está asociada a una mujer —es Penélope quien espera y teje y desteje para ahuyentar pretendientes pero sobre todo para resguardar el regreso de su marido al poder y a la política-, debemos decir que en estas obras de los hermanos Mansilla, no son las mujeres las que esperan sino los hombres. El médico de la novela de Eduarda espera una redención, el militar de la frontera espera una autorización. Ambos están sujetos a la espera. Como no se trata de una espera personal que construye íntimamente el mundo de las emociones personales (aunque esté atravesada por lo personal), estas esperas se configuran fuertemente arraigadas en el afuera del individuo, con un tiempo otro: el tiempo del Estado. El sujeto narrador de Una excursión a los indios ranqueles, esperando una autorización y esperando - una vez regresado a Buenos Aires - un guiño con la opinión pública, que son los lectores de La Tribuna. Sin embargo la espera, en este caso, ha tenido una suerte de bifurcación: Lucio espera una especie de justicia castrense y política y esta se licua. Se licua el objeto de la espera pero, a cambio, recibe otra cosa: el reconocimiento y la admiración de sus lectores en tanto escritor, no solo como el escritor hábil y propio del circuito letrado de época que dirimía la tensión entre el escritor amateur y el escritor profesional, sino como el gran escritor de la frontera. Con lo cual tenemos que Mansilla ha esperado un reconocimiento de su labor como expedicionario y ha obtenido, con la publicación de su relato, otro reconocimiento: el de su labor como escritor. Esta espera, por cierto refiere asuntos personales de la carrera y del lugar de Mansilla en su familia, pero transcurre en un tiempo que no es el tiempo personal, es el de una esfera social y pública. Es decir, se trata de una espera vinculada al mundo de la frontera, al territorio y al mundo de la otredad. Por un lado, el deseo de la otredad y, por el otro, la comprobación de que el acceso a ese mundo no es tan directo y tan diáfano y que entonces, hay que esperar.

En el caso de la novela de Eduarda, que declara en el epígrafe del capítulo IV que la felicidad pública depende de la felicidad privada (Mansilla. E., 1962 [1860]: 25), el relato hace un señalamiento muy particular: el hijo del matrimonio tiene una sensibilidad excesiva. ¿Qué significa esta descripción tan contundente en un relato de corte moral y en una historia de avatares de la vida virtuosa (no olvidemos que el moralismo de la obra está inspirado en El vicario de Wakefield de Oliver Goldsmith): el hecho de que el hijo se sume a la montonera federal marca un pasaje del joven que va de la civilización a la barbarie. En este sentido, el tema de la sensibilidad podríamos decir que se nacionaliza, porque la sensibilidad excedida responde al deseo de la barbarie de la montonera y no a una caracterización universal. Asimismo, el amor del joven por los caballos no responde a una pastoral protestante sino a una preferencia malsana por las correrías que tiene, claramente en la novela, el signo de la barbarie rural. De modo que no se espera otra cosa en la novela que no sea el regreso del hijo desde la barbarie hacia la civilización.

La madre del joven que, según el relato, permanece en la casa preocupada hasta que este vuelve, resulta un personaje melancólico, porque ella no espera la redención del hijo o su reingreso a la civilización, sino su regreso con vida y su resguardo. La espera de esta madre tiene un carácter triste, que se puede asociar a la melancolía, y la concebimos aquí casi como una contraposición a la espera que genera la posibilidad 
y la esperanza de un final bueno. En otros relatos de época podemos corroborar que cuando las madres esperan que sus hijos regresen de la guerra, no lo hacen con temor y con dolor, sino con orgullo patrio. Más allá de si esta es una pose o no, lo cierto es que la angustia de la espera del hijo que está en la guerra se sublima en la esperanza de la construcción de una patria y en la confianza en la guerra como el espacio de construcción de una heroicidad.

El personaje del padre, en cambio, espera al hijo de otro modo. Cuando este va preso, su espera aunque muy dolida es edificante y es el espacio en el que puede elaborar una lectura de la vida de su hijo. "Baste saber que tuve la dicha de hallarlo más desgraciado que culpable, víctima solo de sus propios años y de pérfidos consejeros" (Mansilla, E., 1962 [1860]: 119). Mientras se espera que el hijo salgo de la cárcel se van afianzando, de esta manera, las estructuras, los funcionamientos detallados de las formas de vida: la vida familiar, la vida política, el trabajo.

\section{Tiempo y territorio}

En la novela de Eduarda y en el relato de Una excursión de Lucio puede verse una espera atravesada tanto por el territorio como por el tiempo. Esto se debe a que el tiempo de la espera no es íntimo, es público y depende de una trama estatal. Sin embargo, ese tiempo se realiza en la medida en que se encarna en el mundo privado. Nos preguntamos entonces: ¿es el Estado el que espera? ¿O son los ciudadanos quienes esperan? ¿Es el Estado el que hace esperar? ¿O es el ciudadano quien hace esperar? Dado que hacer esperar es la prerrogativa constante de todo poder, es muy importante tener en cuenta quién es el sujeto de la espera aunque este sea ubicuo.

Pierre Bourdieu, en Sobre el Estado. Cursos en el Collège de France (1989-1992), sostiene que el Estado es el nombre que damos a los principios ocultos, invisibles - para designar a una especie de deus absconditus - del orden social y, al mismo tiempo, tanto del dominio a la vez físico y simbólico como de la violencia física y simbólica. Asimismo, hace referencia al calendario o tiempo estatal a modo de ejemplo y explica justamente la relación que existe entre los actos personales/privados de las personas y las estructuras de la temporalidad social. Dice Bourdieu: "Nuestra percepción de la temporalidad está organizada en función de las estructuras de este tiempo público" (2014: 19).

Desde este análisis, proponemos que la espera es el contrapunto de la melancolía. La melancolía es esa enfermedad del romanticismo decimonónico que prefiere los recursos de la imaginación a aquellos de la razón y que construye al individuo sensible al margen de la sociedad y también del capital. Proponemos que los personajes que están sujetos a la espera están en el centro del relato para garantizar el correcto funcionamiento de una sociedad de afectos fuertemente estructurada en su construcción social y ciudadana. El individuo que espera confía, desea, construye en su sociedad; por el contrario el individuo melancólico va por afuera tanto si busca la trascendencia a ese contexto como si procura la inmanencia, el replegarse sobre sí mismo.

\section{La encrucijada entre un Estado en formación y una intimidad... en transformación}

Es necesario recordar aquí que el siglo XIX argentino es el siglo de la formación del Estado, de modo que sus formas y sus matices siempre están construyéndose. No 
debemos considerar la esfera de lo público-estatal ni el Estado mismo como espacios o instituciones acabadas y sólidas, cerradas, como si se tratara de un dador completo de sentido de la vida de los ciudadanos. Más bien, su carácter es poroso y, al mismo tiempo que se impone y hace esperar, el Estado se va moldeando con el universo de sentimientos de individuos y sociedades.

Por otra parte, un Estado que se modela y se articula a partir de la matriz de interpretación del binomio civilización/barbarie interviene en las historias de la sociedad proponiendo directrices muy concretas. En la literatura, las esperas traman su urdimbre de sujeción: padres que confían en la salvación, coroneles que se enfrentan a sus superiores para no someterse a sus reglas, escritores que encuentran a su público. $Y$ en cada una de estas historias hay gestos precisos en que la espera funciona como una garantía. Solo quien sabe esperar será recompensadx: obtendrá el final feliz, el reconocimiento, pero sobre todo podrá contar la historia.

Los sentimientos y las pasiones de la espera imprimen en la voz de las narraciones de lxs Mansilla, una oportunidad, una posibilidad ineludible: la de narrar la nación. 


\section{Bibliografia}

» Barthes, R. (1991). Fragmentos de un discurso amoroso. México DF, Siglo Veintiuno.

»Batticuore, G. (2005). La mujer romántica. Lectoras, autores y escritores en la Argentina: 1830-1870. Buenos Aires, Edhasa.

" Bourdieu, P. (2014). Sobre el Estado. Cursos en el Collège de France (1989-1992). Barcelona, Anagrama.

" Goldsmith, O. (XXXX). El vicario de Wakefield.

» Iglesia, C. (2002). Mansilla: sueños y vigilias. En La violencia del azar. Ensayo sobre literatura argentina. Buenos Aires, FCE.

》Mansilla, E. (1962 [1860]). El médico de San Luis. Buenos Aires, Eudeba.

» Mansilla, L. V. (1993 [1870]). Una excursión a los indios ranqueles. Buenos Aires, Espasa Calpe.

» Prigent, H. (2005). Les métamorphoses de la dépression. Découvertes Gallimard Réunion des Musées Nationaux Arts. París, Gallimard. 
